\title{
Leader
}

\section{The use of local anaesthetic injections in professional football}

Local anaesthetic use in professional football is one of the greatest taboos in sports medicine. The subject is not covered comprehensively in any sports medicine textbook or review article. Most of the publications citing local anaesthetic use are legal cases from the National Football League (NFL) in which the procedure has been connected with a career ending injury. ${ }^{12}$ There are some candid accounts of how commonplace local anaesthetic use is in the NFL, ${ }^{34}$ and anecdotal evidence suggests that the situation is no different in professional football competitions elsewhere in the world. This includes professional rugby union, in which the practice is officially banned. I have previously published my personal statistics of local anaesthetic injections over a four year period with a professional Australian football team, ${ }^{56}$ but cannot find any similar documentation from other doctors in the sports medicine literature. The attitude of most professional football doctors may be that this practice is a necessary evil that can be performed on certain occasions, but not mentioned or justified in public.

I contend that we end this hypocrisy. Either sports physicians should cease using local anaesthetics in professional football and recommend that the practice be universally banned, or we should study the procedure, speak and write freely about it, and produce guidelines for its rational use.

The effects of officially banning local anaesthetic use, as the International Rugby Board has done, would include an increase in injury prevalence, which is measured by players missing games. This is because players who could take the field with a painkilling injection would be forced onto the sidelines by team physicians adhering to the law. Anecdotal evidence is that the ban in rugby union has not eliminated the practice from occurring altogether. Most of the desire to take the field with injury arises from the players themselves, and if regular doctors refuse to use local anaesthetics, some players find an alternate doctor who is willing to do it in secret. For a suitable injury in a critical match, a player may be able convince his doctor to administer the injection even if it was banned, with both parties officially denying it. Suspending players for testing positive to a local anaesthetic in a drug test is not practical, as these drugs are regularly needed in professional football during the procedure of suturing lacerations. A ban on local anaesthetic use is neither realistic, nor in my opinion necessary, so I will proceed with the argument in favour of the judicious use of local anaesthetic in professional football.

I was never skilled enough to play football at a high level, so have not been in the position of "taking a needle" to play in a football match. I would like to digress with a personal note about a comparable situation. Once in my life, I made enough of a commitment to running training, on a daily basis over many months, to be fit enough to enter a marathon. As a result of my heavy training load, I had the misfortune to be struck down with a case of severe iliotibial band friction syndrome a few weeks before the start of the race. Left entirely to my own pain tolerance, I would not have been able to complete the run. With the benefit of a medical degree and the knowledge that the worst cases of iliotibial band friction syndrome can be cured with surgery, I ran the marathon after injecting myself with bupivacaine over my lateral epicondyle. Fortunately, I completed the race within the half life of the drug and despite worsening my injury, it was eventually cured by surgery and I can now run normally. If I had my time over again, I would have still injected myself to run that race, even though I was allowing myself to physically worsen an injury in doing so. Non-runners may consider this action to be akin to madness, but those colleagues who have run a marathon may appreciate my desire to complete the race.

Local anaesthetic use to numb the pain of an injury should be viewed as a medical procedure like any other. There are risks and there are benefits. If the benefits outweigh the risks, and the patient has expressed, or would have given, informed consent, then the procedure is justified. For the average amateur athlete, the benefits of injecting an injury with local anaesthetic will rarely outweigh the risks. Professional athletes are different animals and we treat them differently from our other patients. We breach standard medical confidentiality on a regular basis by passing on player injury details to coaches, managers, and even journalists, yet players expect this to happen and do not complain. We give professionals the option of returning to play after degenerative injuries, such as a total meniscectomy and chondroplasty (an option which professional players almost always take); we tell our amateur players that they should retire.

The benefits to a professional football player of staying on the field and limiting pain enough to enable optimum performance are often enormous. Faced with a player who had a scapholunate ligament injury asking me to inject his wrist so he could play without pain, I told him I would not recommend it, as when his football career finished he would be likely to suffer with a degenerative wrist joint. $\mathrm{He}$ told me that when he was finished playing, he would "own five houses", implying that he wouldn't need to use his wrist to build any houses. The bottom line is that if a player stays on the field enough, his contract as a professional footballer is extended. If he spends too much time on the injury list - for example, with his wrist in plaster recovering from a wrist reconstruction-then he gets cut by the team and loses his contract.

The potential risks of injecting certain injuries are also numerous. For injections around the groin and knee, a short term complication is a nerve block, which can subject the player to public humiliation if he is suddenly unable to run or kick. In the longer term, tendons and ligaments can rupture, bones can break, and articular cartilage can degenerate with the assistance of painkillers. All of these things can occur without using painkillers. We presume that the likelihood of secondary damage is greater when painkillers are used, but this presumption is based on anecdotal evidence rather than scientific data.

When is the benefit greater than the risk? With respect to retired players experiencing pain, and suffering from osteoarthritis, which are universal risks of football, the answer is usually the same. No matter what their degree of pain, retired players will say that if they had their time again they would still have chosen to play professional football because of the enormous financial and lifestyle benefits. A famous example of this is the case of Curt Marsh, a retired NFL player who eventually suffered a foot amputation from a football injury. ${ }^{7}$ Even though this appeared to have 
resulted from a series of local anaesthetic and cortisone injections to his ankle during his career, Marsh apparently did not file a malpractice lawsuit because he believed that these injections were "part of the game". Further evidence of the risk benefit profile of playing professional football is obvious from reading any table of compensation payments for permanent disability. The amounts of money that body parts are assigned are often merely the weekly earning capacity for a professional football player. Most players would confirm that playing in a critical match is worth more to them than the pain from permanent arthritis in a fifth distal interphalangeal joint.

I believe that the number one injury concern for the vast majority of professional footballers is usually missing the fewest number of matches possible, thereby maximising their career earning potential. With few exceptions, the risk benefit equation for the use of local anaesthetic can be rewritten in the following terms: is this procedure likely to increase or decrease the number of games where a player will take the field in his career? Every game that a player can play with the aid of a local injection is a positive, and the more important the game, the greater the positive to the player. Every potential complication carries the risk of a negative, in that a complication may mean that future games are missed. The same complication may have totally different outcomes for different players. Many complications can be treated with rest or surgical correction in the off season. If a player retains his contract for the next season, then the complication is thrown off as a small price to pay for staying on the field during the regular season. If the player has his contract terminated and he is not offered another by any other team, then from his point of view, the same complication has effectively ended his professional football career.

The sports doctor is in the best position of being able to assess the potential risks of a local anaesthetic injection, which puts the doctor in a difficult position. While a match is in progress, there may not be time to discuss risks with the player, or for the player to ask questions about risks, even though the player should intrinsically always realise that some risks are involved. In the future, there may be less of a tendency for a player to take the Curt Marsh approach that complications from injections should be accepted as part of the game. Players, with encouragement from their lawyers and managers, increasingly want to have their cake and eat it too. They want to be able to earn lucrative amounts of money playing football. They expect their team doctor to both keep them on the playing field and, at the same time, preserve their bodies so they can keep playing indefinitely.

I suspect that much of the reluctance of the sport medicine profession to develop guidelines for the use of local anaesthetic is because of a fear that it will encourage lawsuits. It is foreseeable that once a set of guidelines for "safe" use of local anaesthetic is published, a player could sue his team doctor for refusing to inject an injury with a local anaesthetic. The player may feel he had lost his contract because he missed too many games through injury, or played poorly when he did take the field because of pain from injuries, either of which may not have occurred if the team doctor had given him local anaesthetic injections before games. He may have missed a once in a lifetime opportunity to play in an FA Cup final or Superbowl. This may sound ridiculous, but as soon as the medical profession publishes a guideline that in certain circumstances an injury of a certain type can be safely injected with local anaesthetic, it is likely that a lawyer will ask why his or her client was not offered that procedure. This should not deter us. I hope civilisation ends when doctors totally ignore what is sensible out of deference to the legal profession. Local anaesthetic use in professional football is a "part of the game" and it will remain so. We must develop and publish guidelines regarding its use.

J ORCHARD

South Sydney Sports Medicine

111 Anzac Parade

Kensington NSW 2033

Australia

johnorchard@msn.com.au

1 Polsky S. Winning medicine: professional sports team doctors' conflicts of interest. F Contemp Health Law Policy 1998;14:503-29.

2 Gallup E. Law and the team physician. Champaign, IL, USA: Human Kinetics, 1995.

3 Green T. The dark side of the game: my life in the NFL. New York: Warner Books, 1996.

4 Huizenga R. You're okay, it's just a bruise. New York: St Martin's Press, 1994. 4 Huizenga R. You're okay, it's just a bruise. New York: St Martin's Press, 1994.
5 Orchard J. Management of injuries in the AFL. Sport Health 1999;17:8-14. 6 Orchard J. The use of local anaesthetic in professional football. $\mathcal{F}$ Sci Med Sport 1999;2:S108.

7 Smith S. High cost of glory: former Raider Curt Marsh lost his right foot to amputation, probably because of an injury misdiagnosed by a team doctor. Sports Illustrated 1994;81:156-62.

Please note that the editorial office of British fournal of Sports Medicine has moved. Please send all future communications to: Dr Paul McCrory, British Fournal of Sports Medicine, Centre for Sports Medicine Research \& Education School of Physiotherapy Level 1, 200 Berkeley Street, Parkville, Victoria 3052, Australia. Tel: +61 38344 4118; Fax: +61 38344 3771; Email: bjsm@bmjgroup.com 